\title{
Social Participation and Life Satisfaction Among Widowed Older Adults in China
}

\author{
Yawen $\mathrm{Li}^{1}$, Ling $\mathrm{Xu}^{2^{*}}$, Joohong $\mathrm{Min}^{3}$, Iris $\mathrm{Chi}^{4}$ and $\mathrm{Bin} \mathrm{Xie}^{5}$ \\ ${ }^{1}$ School of Social Work, San Diego State University, San Diego, CA, USA \\ ${ }^{2}$ School of Social Work, University of Texas at Arlington, Arlington, TX, USA \\ ${ }^{3}$ Department of Human Ecology, University of Alberta, Alberta, Canada \\ ${ }^{4}$ School of Social Work, University of Southern California, Los Angeles, CA, USA \\ ${ }^{5}$ School of Community and Global Health, Claremont Graduate University, Claremont, CA, USA \\ *Corresponding author: Xu L, School of Social Work, University of Texas at Arlington, Arlington, Texas, USA, Tel: 5186981372; E-mail: lingxu@uta.edu \\ Rec date: Sep 27, 2016; Acc date: Oct 12, 2016; Pub date: Oct 14, 2016
}

Copyright: (c) $2016 \mathrm{Li} \mathrm{Y}$, et al. This is an open-access article distributed under the terms of the creative commons attribution license, which permits unrestricted use, distribution, and reproduction in any medium, provided the original author and source are credited.

\begin{abstract}
Aim: Little is known about how widowed older adults in China adjust during widowhood. This paper examines the relationship between their changes in social participation following spousal loss and their reported life satisfaction.

Methods: Using two-wave (2000 and 2006) national representative data from China, we regressed measures of widowhood status, changes of social participation, health function, financial strain as well as living arrangement on life satisfaction after adjusting for baseline life satisfaction and other sociodemographic variables.

Results: Increased social participation was related to higher levels of life satisfaction. This study did not find evidence that individuals who experienced widowhood would benefit more compared to those remained married from increasing social participation after spousal loss.

Conclusions: Social participation is one way older adults can potentially improve life satisfaction. In addition to focusing on family support during widowhood, practitioners could consider developing appropriate social activities to engage older adults with particular consideration of those remained widowed for long.
\end{abstract}

Keywords: Chinese; Older adults; Social participation; Widowhood; Life satisfaction

\section{Introduction}

Widowhood in old age has been rated as one of the most stressful negative life events $[1,2]$. Evidence has indicated that widowhood adversely affects physical and psychological well-being [3,4]. Most previous research has focused primarily on the emotional and psychological outcomes of widowhood, whereas the social and behavioral implications of spousal loss [5] received less attention. Behavioral and social adjustments associated with widowhood may be among the most difficult challenges faced by older adults [5]. After spousal loss, individuals may realign their social networks or alter their social activities. However, relatively little evidence is available concerning how social participation changes following spousal loss and how these changes affect the well-being of widowed individuals. Using national representative two-wave data, we examined how changes in social participation during widowhood were associated with the life satisfaction of older Chinese adults.

\section{Social Participation during Widowhood}

There is a lack of consensus on the definition of social participation. Bukov, et al. [6] defined social participation as collective social participation, productive social participation, and political social participation based on shared resources. Other researchers defined social participation as social interactions with individuals other than a spouse, and further classified social participation as formal or informal based on social roles [5,7]. Levasseur et al. [8] conducted a systematic review of definitions of social participation and proposed a taxonomy of social participation composed of six distal to proximal levels of involvement: [1] engaging in an activity in preparation for connecting with others, [2] being with others, [3] interacting with others without performing a specific activity, [4] engaging in an activity with others, [5] helping others, and [6] contributing to society. These levels exist along a continuum and can help distinguish social participation (levels 3 through 6) from parallel but different concepts such as participation (levels 1 through 6) and social engagement (levels 5 and 6). In our study, we focused on a higher level of social participation due to its potential to promote well-being [9] and defined social participation as any interaction with others, participation in activities with others, and being productive toward others or society, which corresponds to levels 3 to 6 in Levasseur et al.s [8] definition.

Researchers have found that changes in social participation may be more related to bereavement than other aging-related changes after spousal loss [7]. However, findings from previous studies on social participation during widowhood have been less consistent. Widowed older adults reduced their participation in social activities [10,11] or reported less social engagement $[7,12]$ after the death of a spouse. Nonetheless, another group of studies found that social interactions became increasingly salient after spousal loss, resulting in an increased level of social involvement among widowed individuals. A study [5] 
Page 2 of 6

showed that widowed older adults had higher levels of social participation than non-widowed adults. Similar findings noted that married older women decreased their involvement in social activities, whereas their widowed counterparts generally increased or maintained their involvement in these activities [13].

The inconsistency in previous research suggests heterogeneity among older adults in terms of changes in social participation after spousal loss. We suspect that the stage of widowhood might contribute to such inconsistency. Social participation after spousal loss could increase due to more interaction with family and friends immediately after the loss [5]. It is also possible that after being freed from caregiving responsibilities, widowed women increased their social participation by rekindling old ties, intensifying existing ties, or developing new ties $[14,15]$. Such support and interaction may gradually dwindle over time as they age and long-term widowed older adults may face decreased social participation due to lost social network connections from their spouse or other life constraints [7]. Differentiating between long-term widowed older adults from those experienced recent widowhoods may help reveal different patterns of social participation after spousal loss.

\section{Social Participation and Life Satisfaction}

The activity theory of aging provides a theoretical framework for examining social participation and well-being in gerontology. This theory begins with the simple propositions that well-being in older adults is promoted by [1] higher levels of participation in social and leisure activities and [2] role replacement when roles must be relinquished [9]. Among various kinds of activities, social activity has been most supported in terms of its association with positive wellbeing $[13,16]$.

Silverstein and Parker [17] used ten-year longitudinal data to follow increases or decreases in activity participation. They found that maintaining or increasing one's range of activities was a buffer against the detrimental effects of functional impairments. Given the previous findings, we suspect participation in different types of social activities may be beneficial especially when older adults experience difficult or stressful life events such as widowhood $[18,19]$.

However, only a handful of studies have examined how social participation after spousal loss is related to well-being $[19,20]$ and even fewer studies have focused on life satisfaction as a health outcome. Even less is known about how spousal loss and subsequent changes in social participation and life satisfaction occur among older Chinese adults, who differ from their Western counterparts in many ways. Older Chinese adults have a lower remarriage rate [21]. Instead of reestablishing their social network through remarriage, they may compensate for their lost social network by connecting more with family members, especially children. In contrast to Western countries that provide many opportunities (e.g. church and club) for social participation, such opportunities are not widely available in China. Instead, residential committees in neighborhood where older adults live may play a more active role in China because they carry out administrative duties assigned by the local government to provide services for the old, the sick, and low-income residents. Taking these different cultural differences into consideration, we included variables concerning living arrangement with children and visits from residential committees in our inquiry.

\section{Our Study}

This study investigated whether changes of social participation after spousal loss among older Chinese adults was related to life satisfaction. Specifically, we tested whether increasing social participation would be associated with higher levels of life satisfaction for old adults. We also examined whether those who were widowed would benefit more from increased social participation in life satisfaction compared to those remained married.

\section{Methods}

\section{Data source and participants}

The data used in the current study came from the panel sample survey of the aged population in urban/rural China conducted by the China research centre on aging (CRCA). The details on survey design, sampling method and data collection process have been described in more detail elsewhere [22]. In brief, the survey was based on a stratified, multistage sample design. In total, 16 divisions representing all north, northeast, east, south central, southwest, and northwest region in the country participated in both 2000 and 2006 survey. For each division, four cities (urban areas) and four counties (rural areas) were selected using the same measure of size. For each city and county, 16 blocks and 16 rural townships were selected. All urban residential communities within those blocks and townships were compiled. From the list, 50 urban residential communities and 50 rural villages were selected at random. In the case of households with more than one person aged 60 years or older, one individual was selected at random. This resulted in a sample of approximately 500 urban and 500 rural older adults in each division. Potential participants were contacted and asked for informed consent. Unavailable subjects (declined to participate, illness, dementia, absent from home, or relocation) were replaced by older adults in the households next to those originally chosen based on the Kish table [22].

The baseline survey featured 14,252 adults aged 60 or older, of whom 6,175 completed the second interview at follow-up. We divided our sample into three groups, namely those remained married (being married at both surveys), those became widowed (being married at baseline but changed to being widowed at follow-up survey) and those remained widowed (being widowed at both surveys). It's possible that those who were widowed could be remarried again but such number in our study is negligible.

\section{Measures}

Life satisfaction is one of the most common markers of successful aging and a key indicator of well-being [23]. Global assessment of life satisfaction was measured at baseline and follow-up using one item question: "In general, are you satisfied with your present life?" Responses were coded on a 5-point Likert scale ranging from 1 to 5, higher score indicating higher life satisfaction. Despite single item measure, research has shown that such short measure is as good as lengthy ones in assessing global well-being [24].

Social participation was measured based on the following questions: [1] Did the residential committee send someone to visit you last year? [2] Did you visit your neighbors last year? [3] Do you go to the following facilities for activities (senior activity center, senior college, retiree activity center, senior daycare center, and playground/parks)? [4] Do you participate in the following activities (neighborhood watch, 
Page 3 of 6

voluntary labor, mutual aid group, mentoring youth, and other volunteer activities)? [5] Do you help your children with looking after the house, house chores, and taking care of grandchildren? Responses to questions 3-5 included multiple items and each response was scored as either $1=$ yes or $0=$ no. The composite score of all responses was calculated (with a range of 0 to 15), with higher scores indicating higher levels of participation. A change score of social participation was calculated by subtracting the score at follow-up from the score at baseline. A negative value in change score indicated decreasing social participation, a positive value indicated increasing social participation, and a value of zero indicated no change.

Baseline sociodemographic information including age, gender, education, self-rated financial strain, and functional health was included as control variables in this study based on the Chinese literature on aging $[25,26]$. In addition, we controlled for functional health using Activities of Daily Living (ADLs) and instrumental activities of daily living (IADLs). All ADL and IADL items were rated on a 3-point Likert scale ranging from "not difficult at all" to "unable to perform the task". The internal consistency of the combined ADL and IADL measures was 0.87. Composite scores including both ADLs and IADLs were calculated (range 9 to 27), with higher scores indicating more limited functionality.

\section{Data Analysis}

We first ran comparison statistics and found that participants who completed the follow-up survey tended to be younger, male, and healthier; they were less likely to live with their children compared with those who dropped out. Data also showed significant group difference in social participation at baseline: Participants who completed the follow-up survey reported higher social participation at baseline compared with those lost to attrition. However, the two groups did not differ in terms of baseline life satisfaction and financial strain (Table 1).

\begin{tabular}{|c|c|c|c|}
\hline & $\begin{array}{l}\text { Follow-Up } \\
(n=6,175) \quad M \quad \text { (SD) } \\
\text { or } \%\end{array}$ & $\begin{array}{l}\text { Dropout } \\
(n=8,077) \quad M \\
(S D) \text { or } \%\end{array}$ & $X^{2}$ or $F(d f)$ \\
\hline Age & $68.07(6.08)$ & $69.83(7.04)$ & $239.63^{* \star *}$ \\
\hline Male & 55.1 & 49.6 & $42.08[1]^{\star * *}$ \\
\hline $\begin{array}{ll}\text { High } & \text { school } \\
\text { education } & \end{array}$ & 21.8 & 23.5 & $5.67[1]^{*}$ \\
\hline Financial strain & $2.17(0.77)$ & $2.18(0.78)$ & 1.39 \\
\hline Functional health & $9.82(2.05)$ & $3.29(0.04)$ & $257.89^{\star * *}$ \\
\hline Living with children & 58.6 & 61.4 & $11.67[1]^{\star \star}$ \\
\hline Social participation & $3.33(1.89)$ & $3.14(2.06)$ & $32.16^{* \star *}$ \\
\hline Life satisfaction & $3.67(.95)$ & $3.67(.95)$ & 0.026 [1] \\
\hline
\end{tabular}

Table 1: Comparison of baseline sociodemographic characteristics between those who completed follow-up survey and those who dropped out.
Additionally, we ran binary logistic regression, which showed baseline life satisfaction was not significant in predicting missing when all the factors were taken into account. Such results suggested our sample is missing at random in regards to life satisfaction (Results not shown here but available upon request).

We ran descriptive statistics to profile our sample characteristics and used ordinary least square (OLS) regressions to test our hypotheses. We first entered baseline life satisfaction, followed by other demographics, social and health variables in blocks. Then we entered our major predictor, change in social participation and lastly tested interaction terms of widowhood status and change in social participation as predictors of life satisfaction.

\section{Results}

Table 2 displays the demographic characteristics of older adults by widowhood status (those who remained married, became widowed, and remained widowed). It's noted that those who remained widowed are predominately female, a phenomenon of gendered widowhood observed almost across the world mostly due to high mortality rate of male, the longevity of female, and the likelihood of female marrying someone older than themselves. Those remained widowed tend to be older and less educated, and they reported more financial strain and poorer health. Over two thirds of them lived with their children. Table 3 shows the results of OLS regression analyses of the relationship between social participation and life satisfaction after controlling for sociodemographic factors and baseline life satisfaction (Tables 2 and 3).

\begin{tabular}{|c|c|c|c|}
\hline & $\begin{array}{l}\text { Became widowed } \\
(n=538)\end{array}$ & $\begin{array}{l}\text { Remained } \\
\text { widowed } \\
(n=2,014)\end{array}$ & $\begin{array}{l}\text { Married } \\
(n=3,623)\end{array}$ \\
\hline & $M(S D)$ or $\%$ & $M(S D)$ or $\%$ & $\begin{array}{ll}M & (S D) \\
\% & \end{array}$ \\
\hline Age & $68.83(6.00)$ & $71.17(6.56)$ & $66.24(5.00)$ \\
\hline Male & 45.4 & 29.8 & 70.7 \\
\hline High school education & 13.4 & 8.8 & 30.1 \\
\hline Financial strain & $2.26(0.80)$ & $2.32(0.78)$ & $2.07(0.74)$ \\
\hline Functional health & $9.93(2.24)$ & $10.16(2.34)$ & $9.62(1.80)$ \\
\hline Living with children & 48.9 & 72.5 & 52.3 \\
\hline $\begin{array}{l}\text { Social participation } \\
\text { (baseline) }\end{array}$ & $3.21(1.81)$ & $3.31(1.85)$ & $3.36(1.92)$ \\
\hline $\begin{array}{l}\text { Social participation } \\
\text { (follow-up) }\end{array}$ & $3.46(2.02)$ & $3.42(1.99)$ & $3.77(2.15)$ \\
\hline $\begin{array}{l}\text { Change in social } \\
\text { participation }\end{array}$ & $0.24(2.31)$ & $0.11(2.27)$ & $0.41(2.40)$ \\
\hline $\begin{array}{l}\text { Life satisfaction } \\
\text { (baseline) }\end{array}$ & $3.65(0.95)$ & $3.59(1.00)$ & $3.73(0.92)$ \\
\hline $\begin{array}{l}\text { Life satisfaction } \\
\text { (follow-up) }\end{array}$ & $3.41(0.92)$ & $3.35(0.92)$ & $3.55(0.90)$ \\
\hline
\end{tabular}

Table 2: Sample characteristics. 
Citation: Li Y, Xu L, Min J, Chi I, Xie B (2016) Social Participation and Life Satisfaction Among Widowed Older Adults in China. J Gerontol Geriatr Res 5: 353. doi:10.4172/2167-7182.1000353

Page 4 of 6

\begin{tabular}{|c|c|c|c|c|c|c|c|c|c|}
\hline & \multicolumn{3}{|c|}{ Model 1} & \multicolumn{3}{|c|}{ Model 2} & \multicolumn{3}{|c|}{ Model 3} \\
\hline & B & Sig. & Std. error & B & Sig. & Std. error & B & Sig. & Std. error \\
\hline Constant & 2.83 & *** & 0.05 & 2.97 & *** & 0.14 & 2.71 & *** & 0.15 \\
\hline Life satisfaction (baseline) & 0.17 & $* * \star$ & 0.01 & 0.17 & $* * *$ & 0.01 & 0.16 & *** & 0.01 \\
\hline Male (ref: female) & & & & -0.02 & & 0.02 & 0.03 & & 0.03 \\
\hline High school education & & & & 0.24 & $* * *$ & 0.03 & 0.22 & $* * *$ & 0.03 \\
\hline Age & & & & 0 & & 0 & 0 & & 0 \\
\hline Become widowed (ref: married) & & & & & & & -0.1 & * & 0.04 \\
\hline Remain widowed (ref: married) & & & & & & & -0.15 & $* \star *$ & 0.03 \\
\hline \multicolumn{10}{|l|}{ Functional health } \\
\hline \multicolumn{10}{|l|}{ Living with children } \\
\hline \multicolumn{10}{|l|}{ Financial strain } \\
\hline \multicolumn{10}{|l|}{ Change in social participation } \\
\hline \multicolumn{10}{|l|}{$\begin{array}{l}\text { Became widowed } \times \text { change in social } \\
\text { participation }\end{array}$} \\
\hline \multicolumn{10}{|l|}{$\begin{array}{l}\text { Remained widowed } \times \text { change in social } \\
\text { participation }\end{array}$} \\
\hline \multirow[t]{3}{*}{ Adjusted R2 } & & 0.033 & & & 0.045 & & & 0.05 & \\
\hline & \multicolumn{3}{|c|}{ Model 4} & \multicolumn{3}{|c|}{ Model 5} & \multicolumn{3}{|c|}{ Model 6} \\
\hline & B & Sig. & Std. Error & B & Sig. & Std. Error & B & Sig. & Std. Error \\
\hline Constant & 3.89 & $* * \star$ & 0.17 & 3.84 & $* * *$ & 0.17 & 3.84 & $\star \star \star *$ & 0.17 \\
\hline Life satisfaction (baseline) & 0.09 & $* * *$ & 0.01 & 0.1 & $* * *$ & 0.01 & 0.1 & $* * *$ & 0.01 \\
\hline Male (ref: female) & 0.02 & & 0.03 & 0.02 & & 0.03 & 0.02 & & 0.03 \\
\hline High school education & 0.13 & 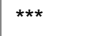 & 0.03 & 0.13 & *** & 0.03 & 0.13 & 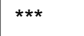 & 0.03 \\
\hline Age & 0 & & 0 & 0 & & 0 & 0 & & 0 \\
\hline Become widowed (ref: married) & -0.08 & & 0.04 & -0.08 & & 0.04 & -0.08 & & 0.04 \\
\hline Remain widowed (ref: married) & -0.1 & $* * \star$ & 0.03 & -0.1 & *** & 0.03 & -0.1 & *** & 0.03 \\
\hline Functional health & -0.01 & & 0.01 & -0.01 & & 0.01 & -0.01 & & 0.01 \\
\hline Living with children & -0.05 & * & 0.02 & -0.05 & * & 0.02 & -0.05 & * & 0.02 \\
\hline Financial strain & -0.24 & $* * *$ & 0.02 & -0.24 & *** & 0.02 & -0.24 & 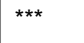 & 0.02 \\
\hline Change in social participation & & & & 0.02 & $* * *$ & & 0.02 & $* * *$ & 0.01 \\
\hline $\begin{array}{l}\text { Became widowed } \times \text { change in social } \\
\text { participation }\end{array}$ & & & & & & & 0.02 & & 0.02 \\
\hline $\begin{array}{l}\text { Remained widowed } \times \text { change in social } \\
\text { participation }\end{array}$ & & & & & & & -0.01 & & 0.01 \\
\hline Adjusted R2 & & 0.085 & & & 0.087 & & & 0.087 & \\
\hline
\end{tabular}

Table 3: OLS models predicting life satisfaction at follow-up. 
Page 5 of 6

Both widowhood status and change in social participation were statistically significant after all other variables were controlled for (Model 5). Compared with those married, those who became widowed and those remained widowed reported reduced life satisfaction (Model 30. But the effect disappeared for those who became widowed once living with children and financial strain (Model 4) and social participation were controlled for (Model 5).

Results in Model 5 also indicated that increase in social participation was significantly associated with increases in life satisfaction. However, the interaction terms, widowhood status and change in social participation, were not statistically significant, suggesting that increased social participation was not associated with additional benefits in life satisfaction.

\section{Discussion}

Using two-wave national representative data, this study examined how change in social participation was related to the life satisfaction of older Chinese adults including those who experienced widowhood. Our results showed that compared to older adults who were married, social participation increased less among participants experiencing widowhood, especially among those remained widowed. This finding corresponds to previous research in which widowed older adults reported less social engagement than their married counterparts $[7,12]$. Several explanations for this observation have been proposed in the literature. Utz et al. [5] suggested that following spousal loss, widowed older adults may exhibit lower levels of social participation than their married counterparts because the experience of losing a spouse serves as a striking reminder of one's own mortality and how disruptive spousal death can be for widowed adults. It is also possible that widowed individuals may simply lack mood and motivation to participate in once enjoyable social activities they previously engaged in with their spouse [7]. However, for individuals who remained widowed during the study period, social isolation, marginalization, and alienation from larger society resulting from spousal loss [27] could possibly have prevented them from further engagement in social activities.

In terms of the association between changes in social participation and life satisfaction, our results showed that older adults who increased their level of social participation were more likely to report higher levels of life satisfaction over time regardless of their marital status. In addition, our results also indicated those who remained in the survey reported higher level of social participation compared to those who dropped out, possibly suggesting a positive relationship between mortality and remaining active. Our result confirmed our first hypothesis and is consistent with previous findings about the beneficial effects of social participation on the well-being of older adults in general $[18,19]$. This finding is in support of activity theory and also demonstrates that increasing social participation in old age is associated with an increased likelihood of life satisfaction. Increased participation in social activities may give older adults a sustained sense of purpose, maintain their physiological efficiency through added activities, and continuously enhance social integration by linking them to family and friends.

This study did not find evidence that older adults who became widowed would benefit more from increased social participation in terms of life satisfaction. Therefore, our second hypothesis was not supported. This finding suggests a general beneficial effect of increased social participation on life satisfaction but no particular effect on older adults who are coping with spousal loss. There might be due to the fact that family support may still matter most for widowed older adults in China. Previous studies have shown that perceived filial piety of children by widowed old adults conferred a buffering effect on selfrated health for those long-term widowed [28]. Such beneficial effect was observed in another study which shows that children listening to older parents, showing consideration and care, and showing respect buffered the deleterious psychological effects of widowhood [29]. It will be interesting for future study to explore the different roles and weight family support and social participation played in widowhood.

The findings from this study expand our understanding of how older adults in China adjust socially during widowhood and how they benefit from increasing social participation on the life satisfaction. However, study results should be interpreted with caution due to several limitations. First, although two-wave panel data were used to test the association between change in social participation and life satisfaction, no causal relationship is guaranteed. The associations identified in this study should be vigorously examined using longitudinal data to trace the within subject trajectory of social participation and life satisfaction and how changes in social participation influence life satisfaction during a long period of time. However, given the paucity of research testing the effects of changes in social participation on well-being among older Chinese adults, this study represents an important step forward. Second, the two-wave data had a 5-year gap between collection points, which contributed to the significant attrition rate due to the advanced age of study participants. Lastly, although we could identify older adults who became widowed between 2000 and 2006, we did not have an exact measurement of the duration of widowhood, which could affect their adjustment to spousal loss. Moreover, the measurement of social participation could be strengthened by including measuring frequency and intensity of such participation.

Despite these limitations, our findings have implications for policies and programs that seek to promote productive aging and assist older adults who experience traumatic events in later life in China. Our study indicated that older adults who increased their level of social participation were more likely to report satisfaction with life. This indicates that social participation is one way older adults can potentially reduce psychological distress and improve their life satisfaction. This study also found that patterns of behavioral adjustment following widowhood depended on the psychological and socioeconomic resources older adults already have. For example, we found financial strain was significantly related to a decreased life satisfaction. Life satisfaction at baseline was positively associated with life satisfaction at follow-up. This finding suggests that spousal loss and its ensuing grief may be structurally determined and diversified by the particular resources available to each individual experiencing widowhood. Practitioners should consider both the material and psychological resources available to widowed older adults to better understand the adjustment process.

\section{References}

1. Bisconti TL, Bergeman CS, Boker SM (2004) Emotional well-being in recently bereaved widows: A dynamical systems approach. Gerontol B Psychol Sci Soc Sci 59: P158-P167.

2. Fry PS (2001) The unique contribution of key existential factors to the prediction of psychological well-being of older adults following spousal loss. Gerontologist 41: 69-81.

3. Christakis NA, Allison PD (2006) Mortality after the hospitalization of a spouse-Reply. New Engl J Med 354: 2190-2191. 
Citation: Li Y, Xu L, Min J, Chi I, Xie B (2016) Social Participation and Life Satisfaction Among Widowed Older Adults in China. J Gerontol

Page 6 of 6

4. Elwert F, Christakis NA (2008) The effect of widowhood on mortality by the causes of death of both spouses. Am J Public Health 98: 2092-2098.

5. Utz RL, Carr D, Nesse R, Wortman CB (2002) The effect of widowhood on older adults' social participation: An evaluation of activity, disengagement, and continuity theories. Gerontologist 42: 522-533.

6. Bukov A, Maas I, Lampert T (2002) Social participation in very old age: Cross-sectional and longitudinal findings from BASE. Gerontol B Psychol Sci Soc Sci 57: P510-P517.

7. Janke MC, Nimrod G, Kleiber DA (2008) Reduction in leisure activity and well-being during the transition to widowhood. J Women Aging 20: 83-98.

8. Levasseur M, Richard L, Gauvin L, Raymond E (2010) Inventory and analysis of definitions of social participation found in the aging literature: proposed taxonomy of social activities Soc Sci Med 71:2141-2149.

9. Havighurst RJ (1963) Successful aging. Processes of aging: Social and psychological perspectives 1: 299-320.

10. Patterson I (1996) Participation in leisure activities by older adults after a stressful life event: The loss of a spouse. Int J Aging Hum Dev 42: 123-142.

11. Bennett KM (1998) Gender and longitudinal changes in physical activities in later life. Age Ageing 27: 24-28.

12. Bennett KM (2005) Psychological wellbeing in later life: The longitudinal effects of marriage, widowhood and marital status change. Int J Geriatr Psych 20: 280-284.

13. Anaby D, Miller WC, Jarus T, Eng JJ, Noreau L (2011) Participation and well-being among older adults living with chronic conditions. Soc Indic Res 100: 171-183.

14. Zettel LA, Rook KS (2004) Substitution and compensation in the social networks of older widowed women. Psychol Aging 19: 433-443.

15. Cheng ST, Chan ACM (2006) Relationship with others and life satisfaction in later life: Do gender and widowhood make a difference? Gerontol B Psychol Sci Soc Sci 61: P46-P53.

16. Adams KB, Leibbrandt S, Moon H (2011) A critical review of the literature on social and leisure activity and wellbeing in later life. Ageing Soc 31: 683-712.
17. Silverstein M, Parker MG (2002) Leisure activities and quality of life among the oldest old in Sweden. Res Aging 24: 528-547.

18. Ha JH (2008) Changes in support from confidants, children, and friends following widowhood. J Marriage Fam 70: 306-318.

19. Janke MC, Nimrod G, Kleiber DA (2008) Leisure activity and depressive symptoms of widowed and married women in later life. J Leisure Res 40: 250-266.

20. Hong SI, Hasche L, Bowland S (2009) Structural relationships between social activities and longitudinal trajectories of depression among older adults. Gerontologist 49: 1-11.

21. Wang Q, Zhou Q (2010) China's divorce and remarriage rates: Trends and regional disparities. J Divorce Remarriage 51: 257-267.

22. He W (2007) Health and health care of the older population in urban and rural China: 2000: US Census Bureau.

23. Tate RB, Lah L, Cuddy TE (2003) Definition of successful aging by elderly Canadian males: The Manitoba follow-up study. Gerontologist 43: 735-744.

24. Larsen RJ, Diener E, Emmons RA (1986) Affect intensity and reactions to daily life events. J Pers Soc Psychol 51: 803.

25. Liu GP, Zhang Z (2004) Sociodemographic differentials of the self-rated health of the oldest-old Chinese. Popul Res Policy Rev 23: 117-133.

26. Zhang W, Liu G (2007) Childlessness, psychological well-being, and life satisfaction among the elderly in China. J Cross Cult Gerontol 22: 185-203.

27. Rosow I (1973) The social context of the aging self. The Gerontologist 13: 82-87.

28. Li Y, Chi I, Krochalk PC, Xu L (2011) Widowhood, family support, and self-rated health among older adults in China. Int J Soc Welf 20: S72-S85.

29. Li L, Liang J, Toler A, Gu S (2005) Widowhood and depressive symptoms among older Chinese: do gender and source of support make a difference? Soc Sci Med 60: 637-647. 